\title{
Z-SHAPED DIPOLE ANTENNA AND ITS FRACTAL ITERATIONS
}

\author{
Mustafa H. Abu Nasr \\ Engineering Department, Faculty of Engineering and Information Technology, Al- Azhar \\ University, Gaza, Palestine.
}

\begin{abstract}
Z-shaped dipole and fractal Z-shaped dipole antennas made of wires are introduced. Theses antennas exhibit lower resonant frequencies and small space occupations. The performance characteristics of the proposed antennas are examined and compared with successive iterations for the same wire length. The radiation properties are considered including input impedance and VSWR as functions of frequency. Also the comparison between the third iteration of fractal Z-shaped dipole antenna and linear dipole antenna with the same wire length are presented.
\end{abstract}

\section{KEYWORDS}

Wire antennas, fractal, MoM, input impedance, resonant, gain, VSWR, current distribution, polarization

\section{INTRODUCTION}

Wire-type antennas are made of conducting wires and are generally easy to construct, thus the cost is normally low. Examples include dipoles, monopoles, loops, helices, Yagi-Uda and logperiodic antennas. Arrays of dipoles-the famous form of the wire antennas- are commonly used as base-station antennas in mobile systems $[1,2]$.

Fractal is a word that describes the complex geometries that are created through successive iterations when applying a geometric generator to a simple Euclidean basis or iteration geometry. In general, there are no strict guidelines as to what geometric shapes constitute fractal geometry. However, there are geometric properties used to describe fractals such as self-similarity, in which a small region of the geometry repeats the whole geometry and space-filling [3]. Mathematically, the fractal geometry is principally defined by the characteristic of fractal-dimensions. The fractaldimension can be interpreted as measure of the space-filling properties and complexity of the fractal shape [4]. Fractals provide a new approach to antenna design. The geometrical properties of fractals challenge the traditional constraints of classical antennas. Fractals can be used in two ways to enhance antenna designs. The first method is in the design of miniaturized antenna elements. This can lead to antenna elements which are more discrete for the end user. The second method is to use the self-similarity in the geometry to design antennas which are multiband. This would allow the operator to incorporate several aspects of their system into one antenna. Antenna elements utilizing both these tactics can be incorporated into highly advanced array and smart antenna designs [4-9].

To obtain completely accurate solutions for wire antennas, the current on the wire must be solved for, subject to the boundary condition that the tangential electric field is zero along the wire. This approach gives rise to an integral equation which can be solved by numerical methods [1].

DOI : $10.5121 /$ ijnsa.2013.5512 
The method of moments (MoM) solution is a numerical procedure for solving the electric field integral equation. Basis functions are chosen to represent the unknown currents (i.e., triangular basis functions). Testing functions are chosen to enforce the integral equation on the surface of the wires. With the choice of basis and testing functions, a matrix approximating the integral equation is derived. If this matrix is inverted and multiplied by the local sources of electric field, the complex magnitudes of the current basis functions are derived. All antenna performance parameters can be determined from the derived current distribution. In this paper commercial software (NEC-win professional) is used to obtain all the radiation characteristics of the proposed S-shaped antennas. [1,10]

\section{Z-ShaPed Dipole Antenna (ZDA) And FraCtal Z-ShaPed Dipole ANTENNA}

\subsection{Antenna Structure}

This antenna is made of a Z-shaped thin wire and is fed symmetrically as shown in Figure 1. The antenna is located in the $x z$-plane. The fractal first, second and third iterations of Z-shaped dipole antenna are depicted in figures 2, 3 and 4 . Each iteration is formed by replacing the half of the free arm of Z-shape by another Z-shape. All of these antennas have the same wire length (202 $\mathrm{cm}$ ) and a radius of $0.1 \mathrm{~cm}$. The MoM with one-volt delta gap source is applied to theses antennas. The previous antennas occupy different spaces as shown in the figures and table 1 . The antenna performance properties are obtained using commercial software (NEC-WIN Pro V.1.6) [11].

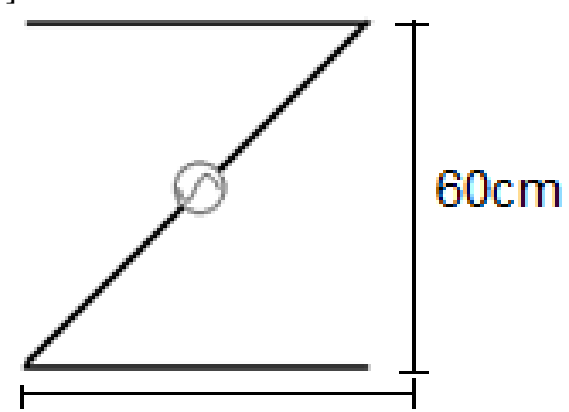

$60 \mathrm{~cm}$

Figure1.a .Z-shaped dipole antenna

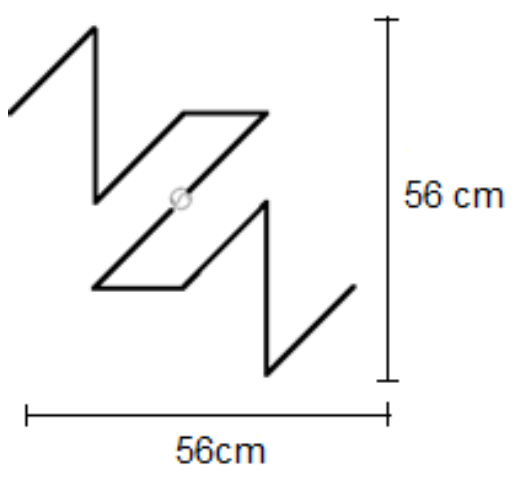

Figure 2a. $1^{\text {st }}$ iteration of fractal ZDA

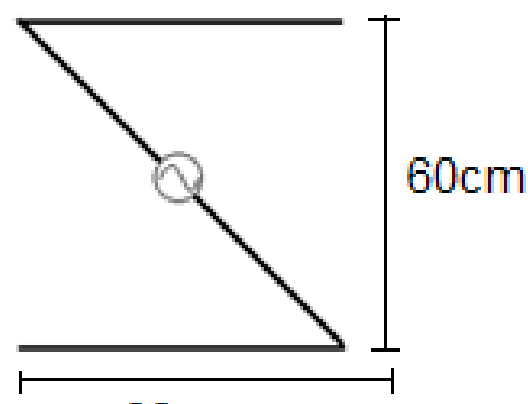

$60 \mathrm{~cm}$

Figure 1.b. Inverted Z-shaped antenna

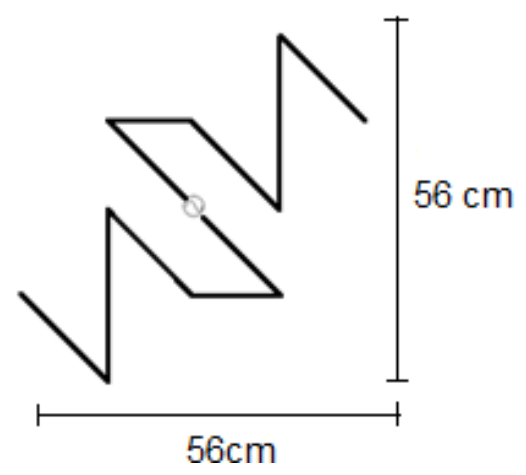

Figure $2 \mathrm{~b} .1^{\text {st }}$ iteration of fractal inverted ZDA 
International Journal of Network Security \& Its Applications (IJNSA), Vol.5, No.5, September 2013

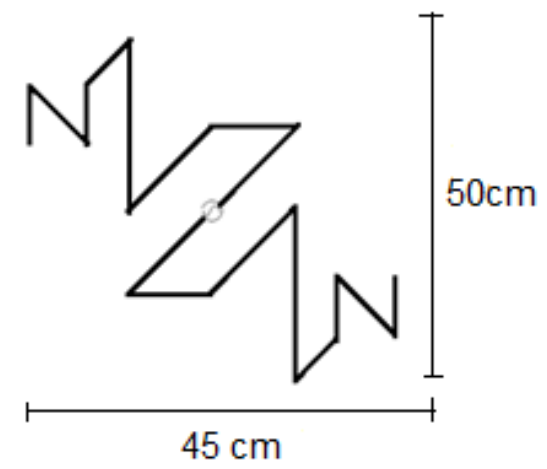

Figure 3 a. $2^{\text {nd }}$ iteration of fractal ZDA
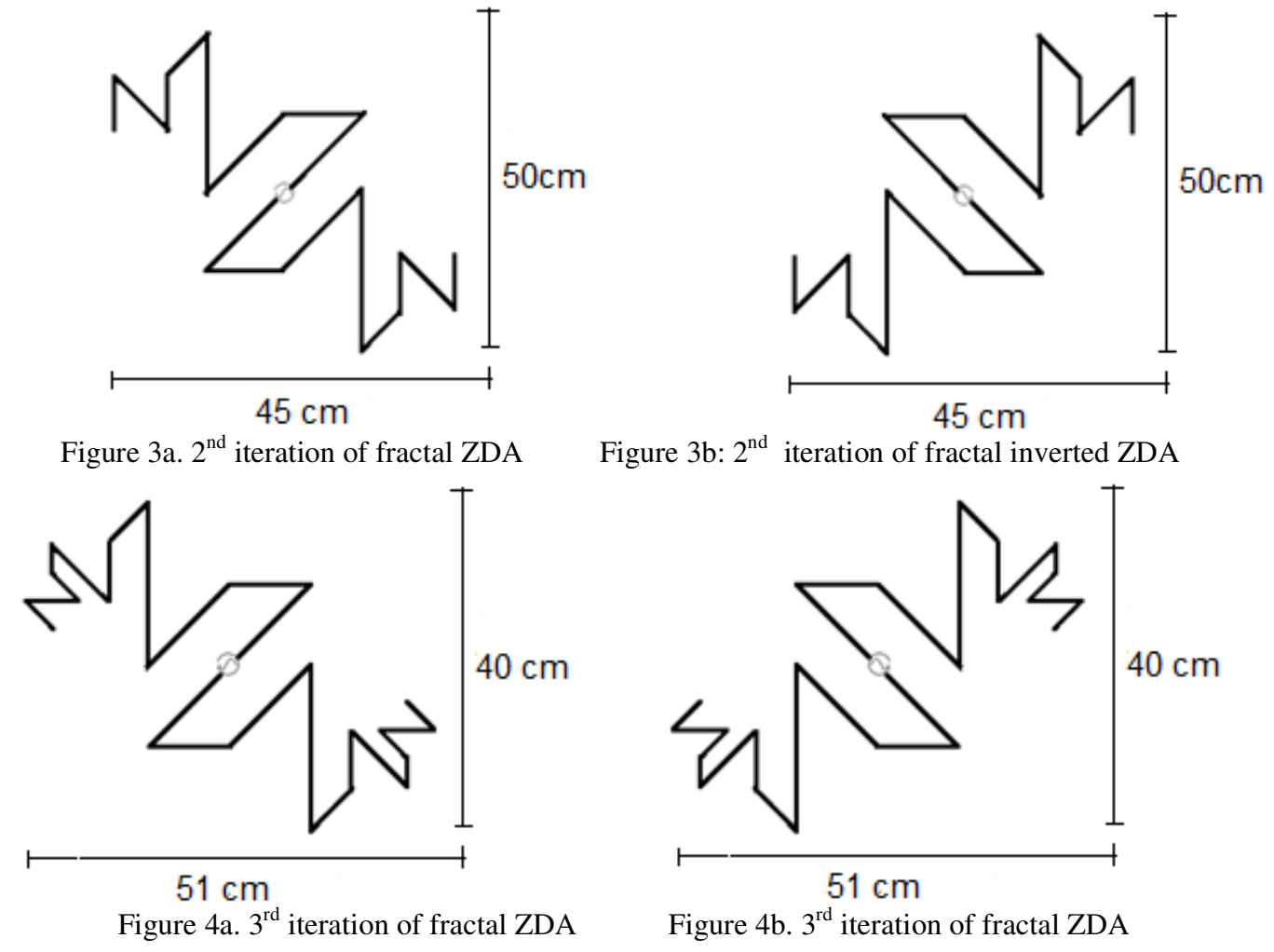

Figure $3 b: 2^{\text {nd }}$ iteration of fractal inverted ZDA

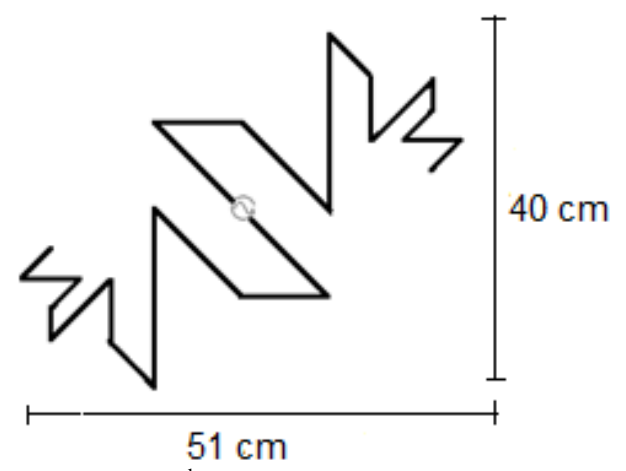

Figure 4 b. $3^{\text {rd }}$ iteration of fractal ZDA

Table 1. Space dimensions for ZDA and fractal ZDA

\begin{tabular}{|c|c|}
\hline Antenna type & Space dimension \\
\hline Z-shaped dipole antenna & $60 \mathrm{~cm} \mathrm{x60cm}$ \\
\hline $1^{\text {st }}$ iteration fractal Z-shaped dipole antenna & $56 \mathrm{~cm} \times 56 \mathrm{~cm}$ \\
\hline $2^{\text {nd }}$ iteration fractal Z-shaped dipole antenna & $50 \mathrm{~cm} \times 43 \mathrm{~cm}$ \\
\hline $3^{\text {rd }}$ iteration fractal Z-shaped dipole antenna & $51 \mathrm{~cm} \mathrm{x} 40 \mathrm{~cm}$ \\
\hline
\end{tabular}

\subsection{Results and Discussions}

\subsubsection{The Input Impedance and The Resonant Performance}

The input impedance as a function of frequency for ZDA and the successive fractal iterations of ZDA are presented in figures 5 and 6. 
International Journal of Network Security \& Its Applications (IJNSA), Vol.5, No.5, September 2013

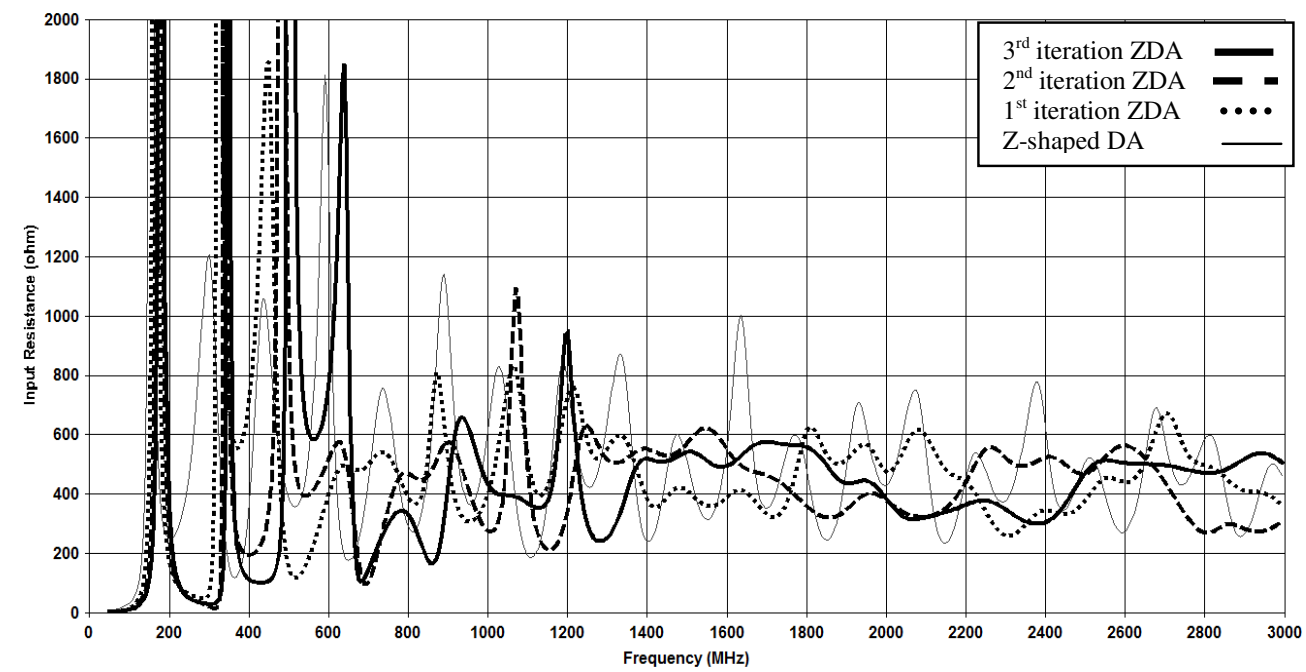

Figure 5. The input resistances of ZDA and the successive fractal iterations of ZDA

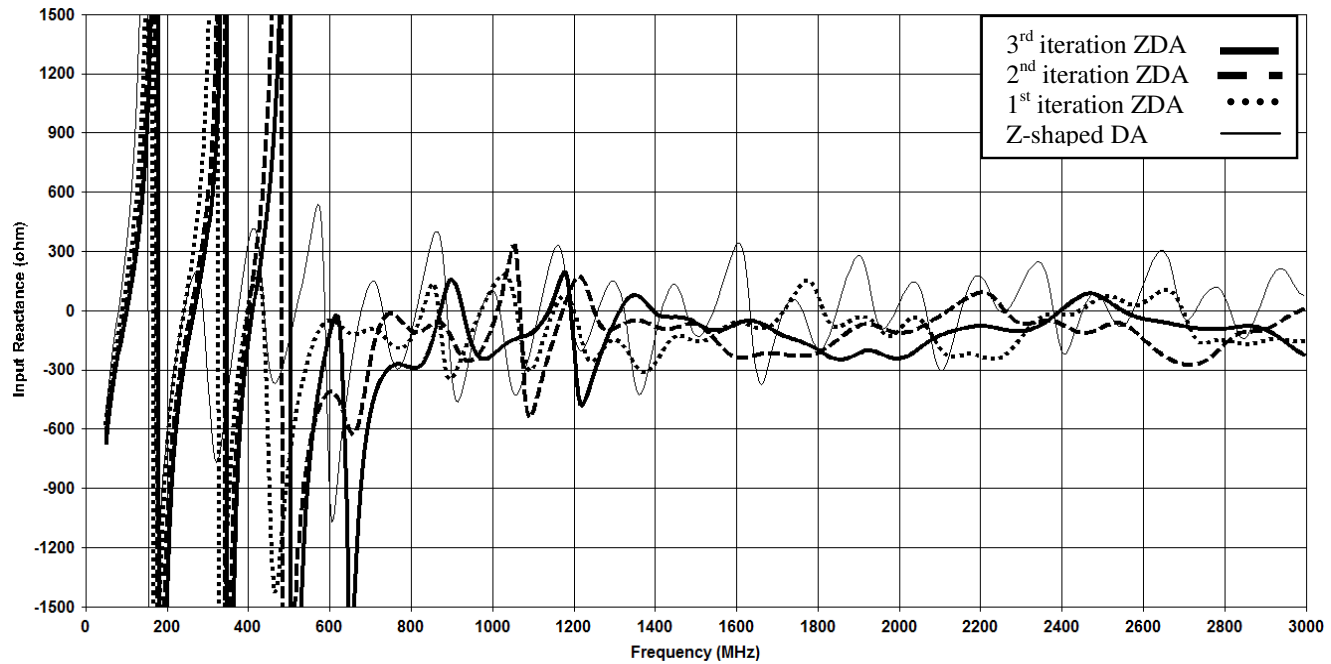

Figure 6. The input reactance of ZDA and the successive fractal iterations of ZDA

From these figures (5 and 6) it is clear that the input resistance for the higher fractal iteration of ZDA more stable than ZDA especially for high frequencies. The fractal ZDA loses its resonant properties when the successive iteration increased and the antenna becomes a wideband antenna. For this property, these types of antennas can be used in many applications such as GSM bands, Bluetooth, Wi-Fi and other RF applications. Also the increased of successive iteration values forced the antenna reactance to become capacitive.

The resonance performance characteristics of the first, second and third iterations of fractal ZDA are presented in tables 2, 3 and 4. The second and third iterations, both have 7 resonant frequencies in the band $f<3000 \mathrm{MHz}$ and the first iteration has 8 resonant frequencies at the same band. 
International Journal of Network Security \& Its Applications (IJNSA), Vol.5, No.5, September 2013

Table 2. The resonance performance characteristics of the third iteration of fractal ZDA

\begin{tabular}{|c|c|c|}
\hline \multicolumn{2}{|c|}{ Third iteration } \\
\hline $\begin{array}{c}\text { Resonant Frequency } \\
(\mathrm{MHz})\end{array}$ & $\begin{array}{c}\text { Resonant } \\
\text { Resistances }(\Omega)\end{array}$ & $\begin{array}{c}\text { VSWR } \\
\text { at Z }=300 \Omega\end{array}$ \\
\hline 100 & 9 & 30 \\
\hline 267 & 400 & 7.5 \\
\hline 411 & 105 & 2.8 \\
\hline 872 & 182 & 1.6 \\
\hline 1138 & 355 & 1.2 \\
\hline 1313 & 280 & 1.1 \\
\hline 2397 & 300 & 1 \\
\hline
\end{tabular}

Table 3. The resonance performance characteristics of the second iteration of fractal ZDA

\begin{tabular}{|c|c|c|}
\hline \multicolumn{2}{|c|}{ Second iteration } \\
\hline $\begin{array}{c}\text { Resonant Frequency } \\
(\mathrm{MHz})\end{array}$ & $\begin{array}{c}\text { Resonant } \\
\text { Resistances }(\Omega)\end{array}$ & $\begin{array}{c}\text { VSWR } \\
\text { at Z }=300 \Omega\end{array}$ \\
\hline 97 & 18 & 32 \\
\hline 258 & 60 & 6.4 \\
\hline 400 & 195 & 1.5 \\
\hline 1011 & 274 & 1.1 \\
\hline 1172 & 235 & 1.3 \\
\hline 2120 & 330 & 1.1 \\
\hline
\end{tabular}

Table 4. The resonance performance characteristics of the first iteration of fractal ZDA

\begin{tabular}{|c|c|c|}
\hline \multicolumn{3}{|c|}{ First iteration } \\
\hline $\begin{array}{c}\text { Resonant Frequency } \\
(\mathrm{MHz})\end{array}$ & $\begin{array}{c}\text { Resonant } \\
\text { Resistances }(\Omega)\end{array}$ & $\begin{array}{c}\text { VSWR } \\
\text { at Z }=300 \Omega\end{array}$ \\
\hline 88 & 13 & 30 \\
\hline 241 & 73 & 4.3 \\
\hline 398 & 650 & 2.2 \\
\hline 828 & 380 & 1.3 \\
\hline 971 & 320 & 1.1 \\
\hline 1150 & 427 & 1.4 \\
\hline 1717 & 323 & 1.1 \\
\hline 2444 & 330 & 1.1 \\
\hline
\end{tabular}

\subsubsection{The Voltage Standing Wave Ratio VSWR}

The VSWR at $Z_{\circ}=300$ for the ZDA and fractal ZDA is shown in Figure 7. 
International Journal of Network Security \& Its Applications (IJNSA), Vol.5, No.5, September 2013

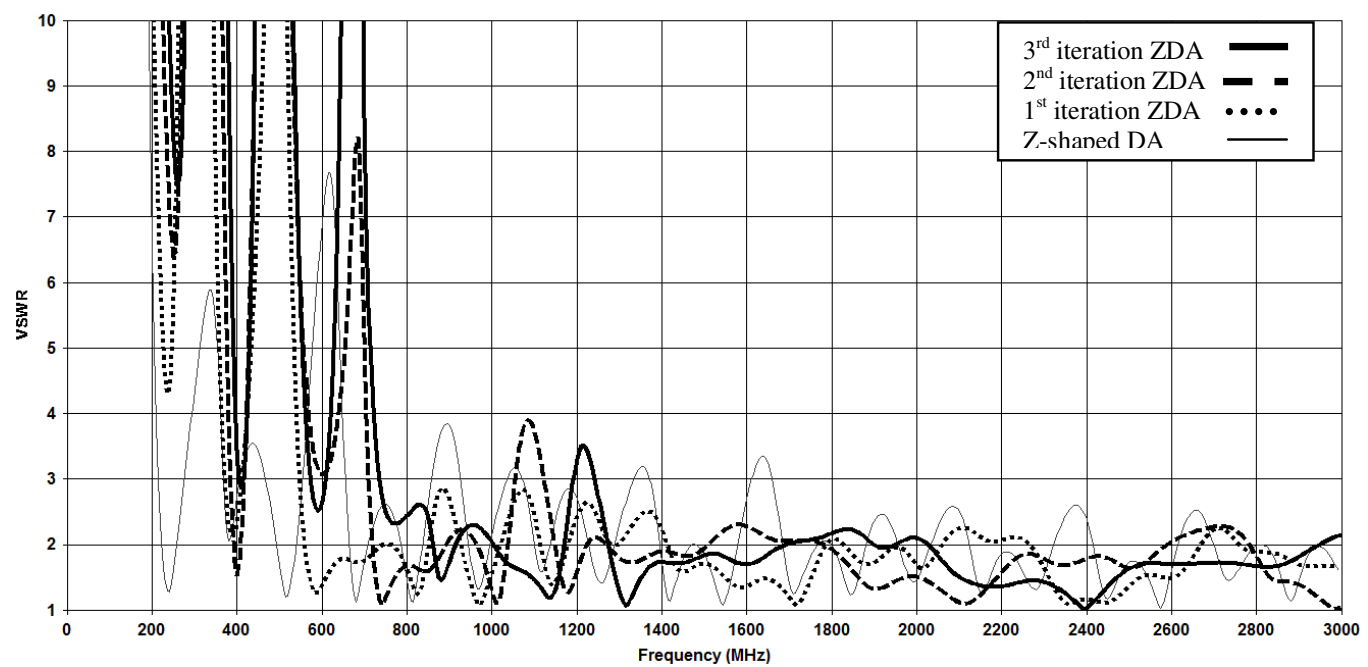

Figure 7. The VSWR of ZDA and the successive fractal iterations of ZDA at $Z_{\circ}=300$

\subsubsection{The Radiation Pattern and the Gain}

Typical power radiation patterns at $400 \mathrm{MHz}, 900 \mathrm{MGHz}$ and $1900 \mathrm{MHz}$ for ZDA and the successive fractal iterations of ZDA in the free space are given in Figures 8to 13.

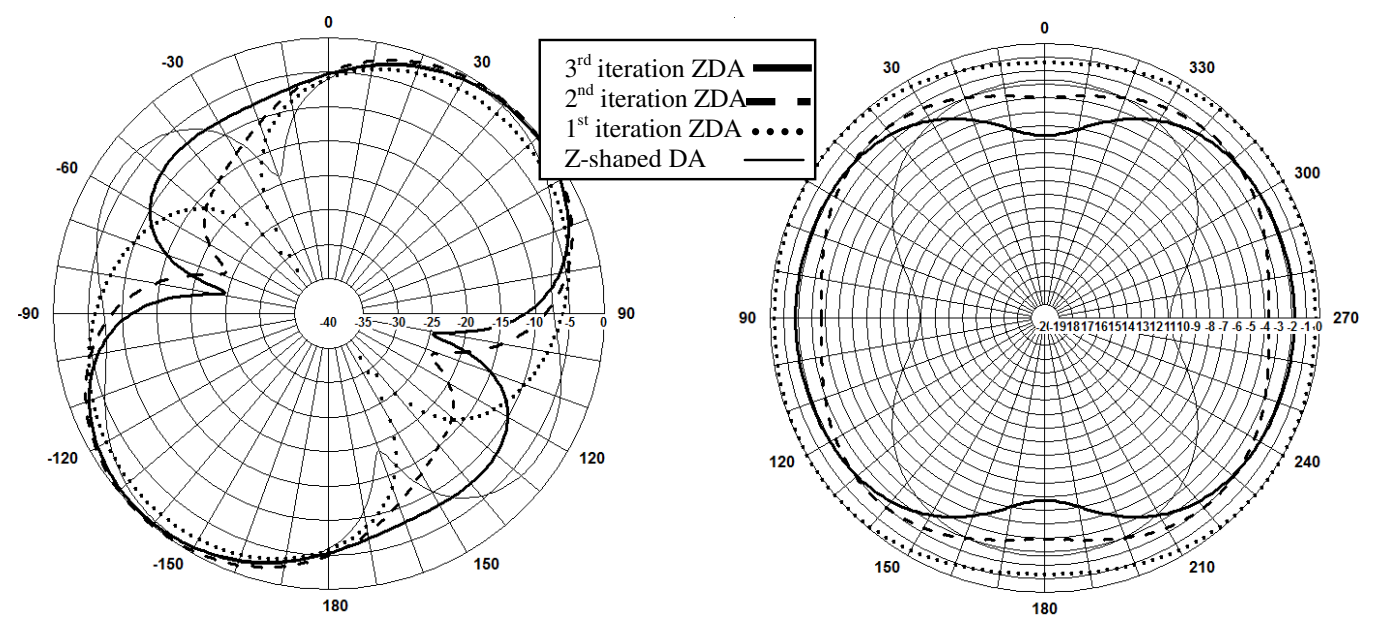

Figure 8. Power radiation pattern in $x z-$ plane at $400 \mathrm{MHz}$

Figure 9. Power radiation pattern in $x y$ plane at $400 \mathrm{MHz}$ 
International Journal of Network Security \& Its Applications (IJNSA), Vol.5, No.5, September 2013

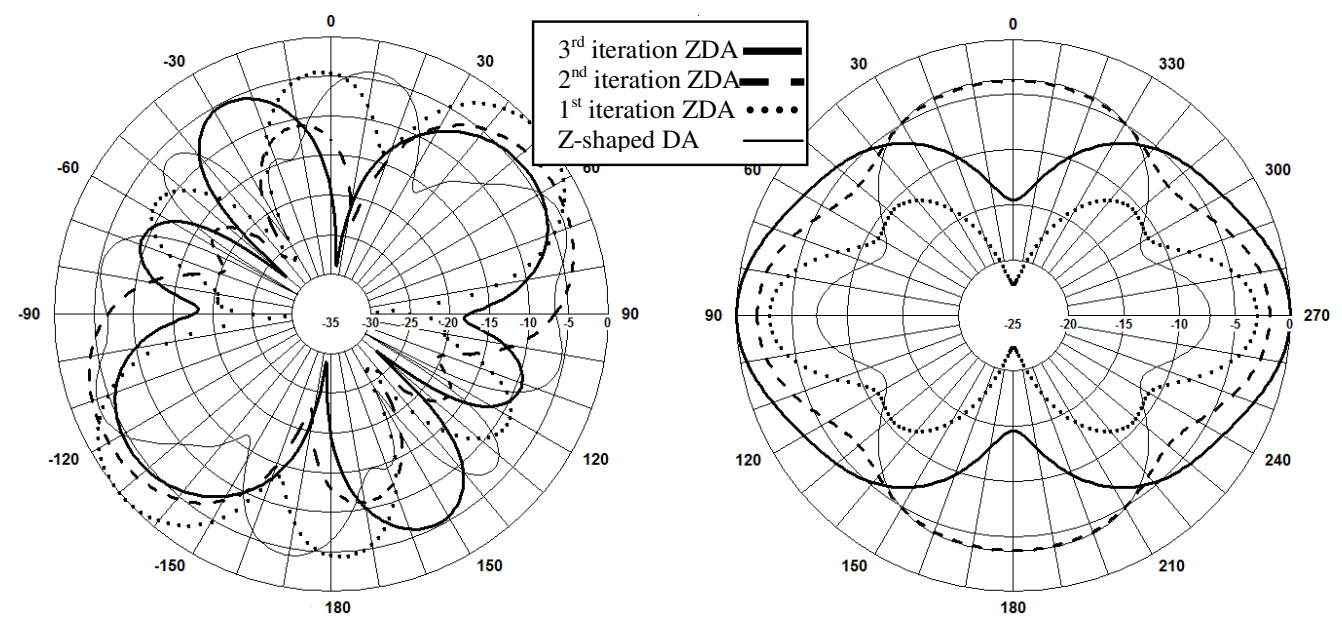

Figure10. Power radiation pattern in $x z$-plane at $900 \mathrm{MHz}$

Figure11. Power radiation pattern in $x y$ - plane at $900 \mathrm{MHz}$

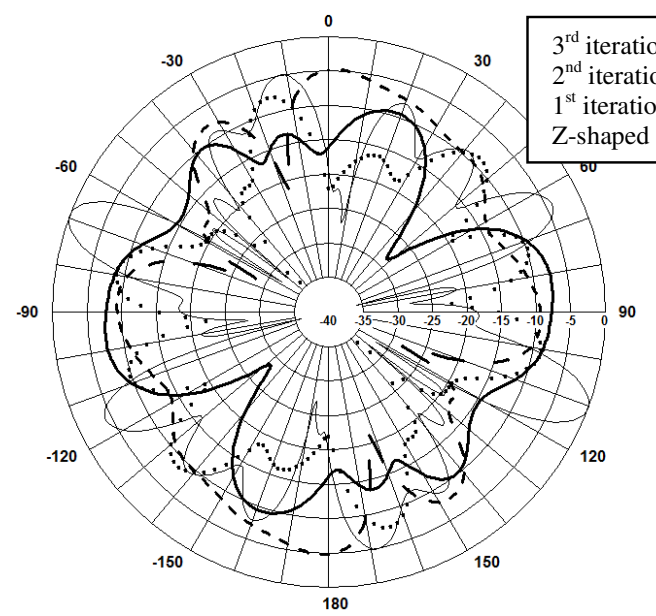

Figure 12. Power radiation pattern in $x z$-plane at $1900 \mathrm{MHz}$
Figure 13. Power radiation pattern in $x y$-plane at $1900 \mathrm{MHz}$

The gain of theses antennas at the previous frequencies are presented in table 4

Table 4. The total gain in $\mathrm{dB}$ for ZDA and the successive fractal iterations of ZDA at different Frequencies

\begin{tabular}{|c|c|c|c|}
\hline Antenna type & $400 \mathrm{MHz}$ & $900 \mathrm{MHz}$ & $1900 \mathrm{MHz}$ \\
\hline Z-shaped dipole antenna & 4.4 & 4.1 & 10 \\
\hline $1^{\text {st }}$ iteration fractal Z-shaped dipole antenna & 3 & 7.5 & 2.2 \\
\hline $2^{\text {nd }}$ iteration fractal Z-shaped dipole antenna & 5.1 & 4.9 & 5.5 \\
\hline $3^{\text {rd }}$ iteration fractal Z-shaped dipole antenna & 4.8 & 4.53 & 3.9 \\
\hline
\end{tabular}




\subsubsection{The Current Distribution}

The current distribution at $400 \mathrm{MHz}, 900 \mathrm{MHz}$ and $1900 \mathrm{MHz}$ for ZDA and the successive fractal iterations of ZDA are given in Figures 14 to 16. It is clear that the current distribution on the second iteration more efficient than the others at $400 \mathrm{MHz}$ and $1900 \mathrm{MHz}$ where the third iteration is the best at $900 \mathrm{MHz}$.

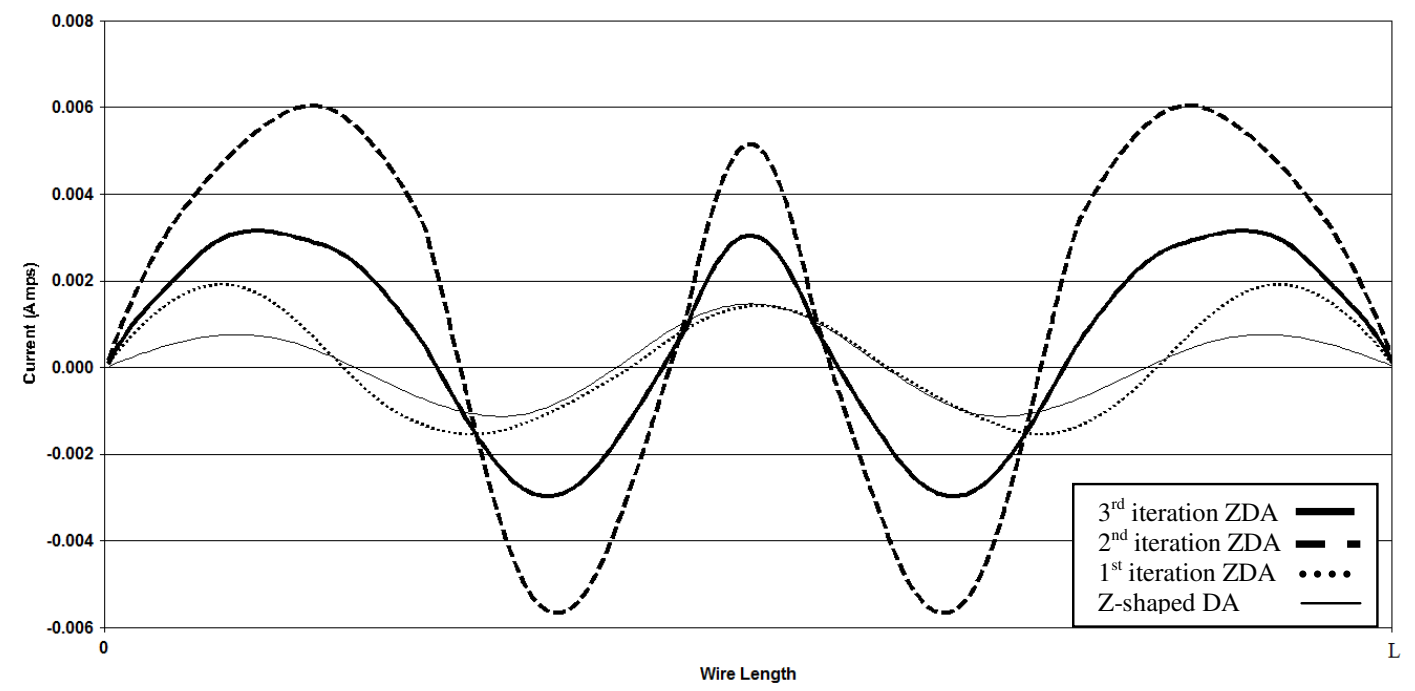

Figure 14. The current distribution for the ZDA and the successive fractal iterations of ZDA at the 400 $\mathrm{MHz}$

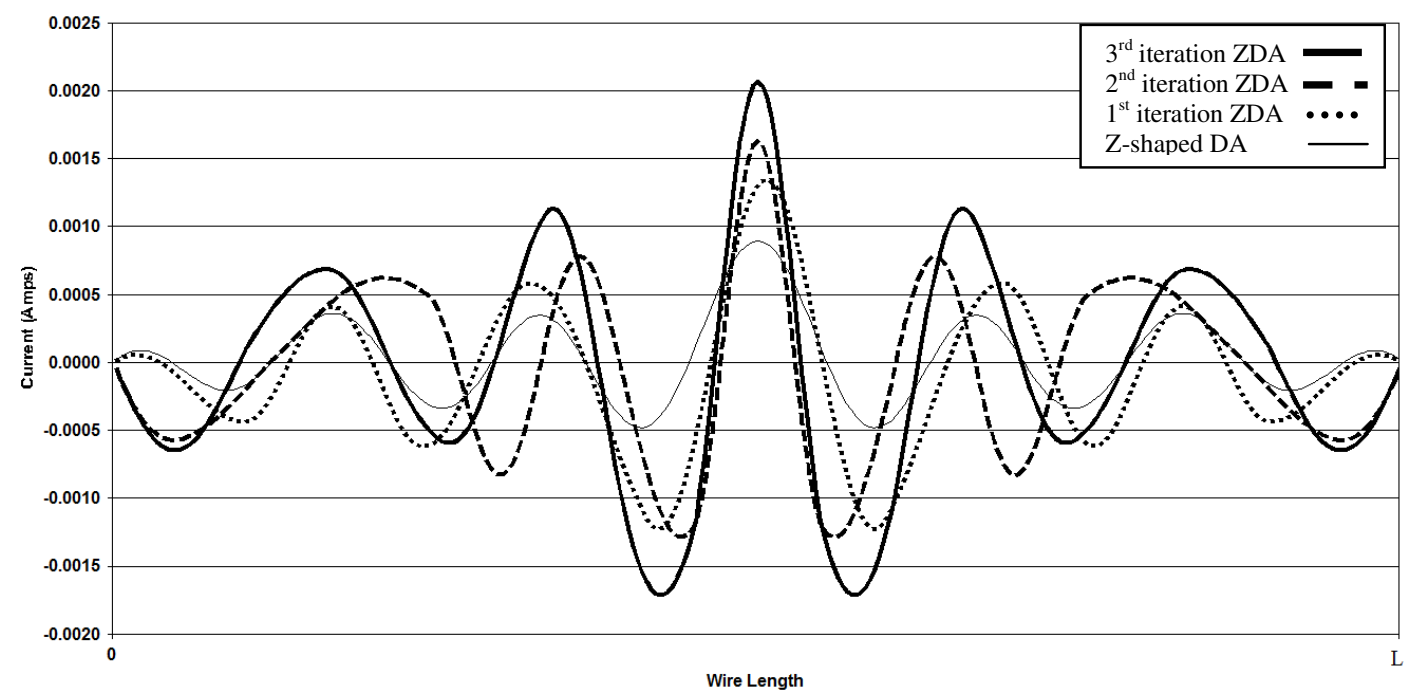

Figure 15. The current distribution for the ZDA and the successive fractal iterations of ZDA at the 900 $\mathrm{MHz}$ 
International Journal of Network Security \& Its Applications (IJNSA), Vol.5, No.5, September 2013

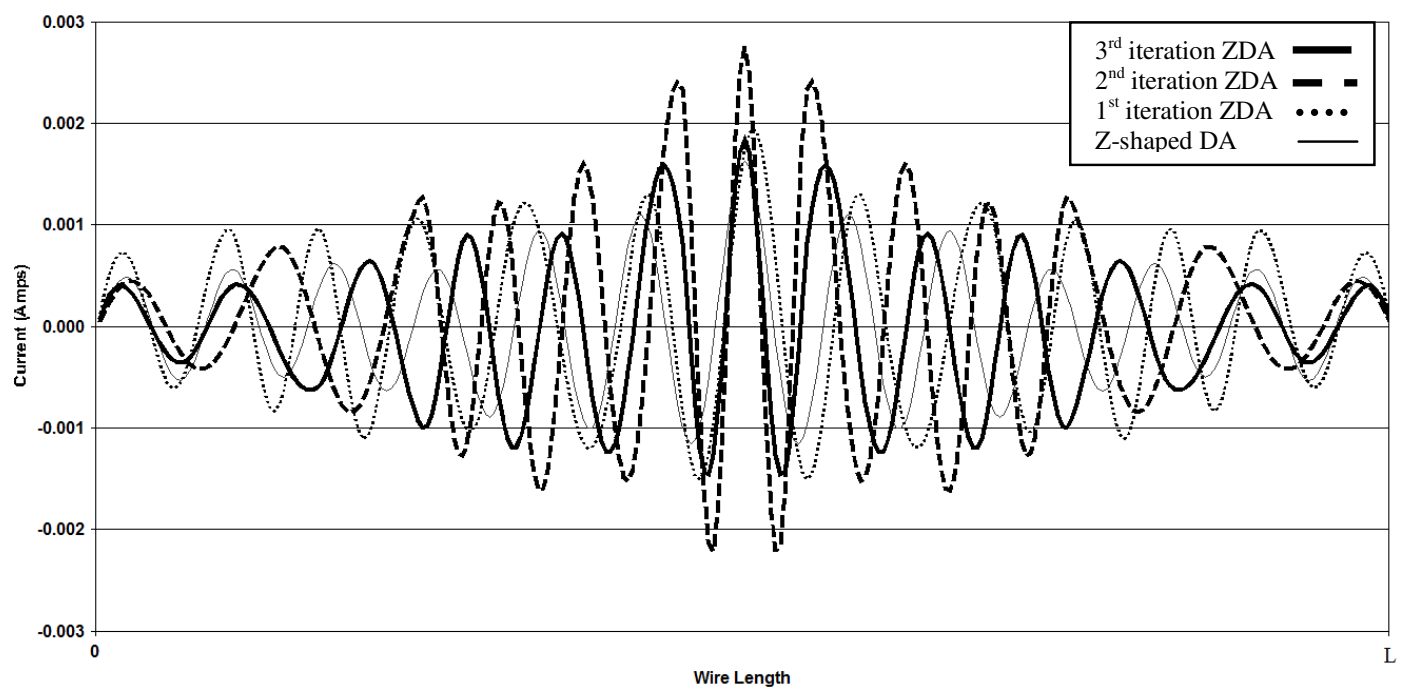

Figure 16. The current distribution for the ZDA and the successive fractal iterations of ZDA at the 1900 $\mathrm{MHz}$

\subsubsection{Polarization and Axial Ratio}

The axial ratio (AR) of the ZDA and successive fractal iterations of ZDA is depicted in figure 17. from this figure and the simulation results, it is clear that the ZDA and fractal ZDA radiate left elliptically polarized (LEP) waves where the inverted ZDA and fractal inverted ZDA radiate right elliptically polarized (REP) waves.

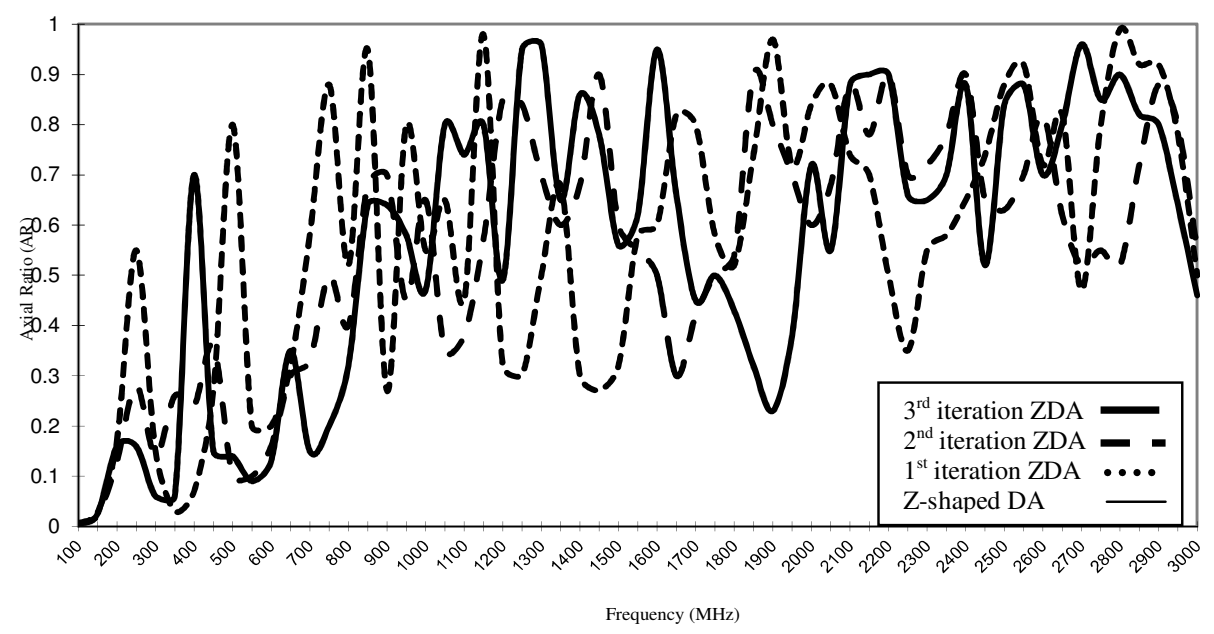

Figure 17. The axial ratio for the ZDA and the successive fractal iterations of ZDA 
International Journal of Network Security \& Its Applications (IJNSA), Vol.5, No.5, September 2013

\section{Comparison Between The Third Iteration OF Z-ShaPed DiPOle ANTENNa ANd Linear Dipole}

Figures 18, 19 and 20 present the input resistance, input reactance and VSWR for the third iteration of fractal ZDA and linear dipole with the same wire length. Also the radiation patterns and current distribution are represented in figures 21 to 26.

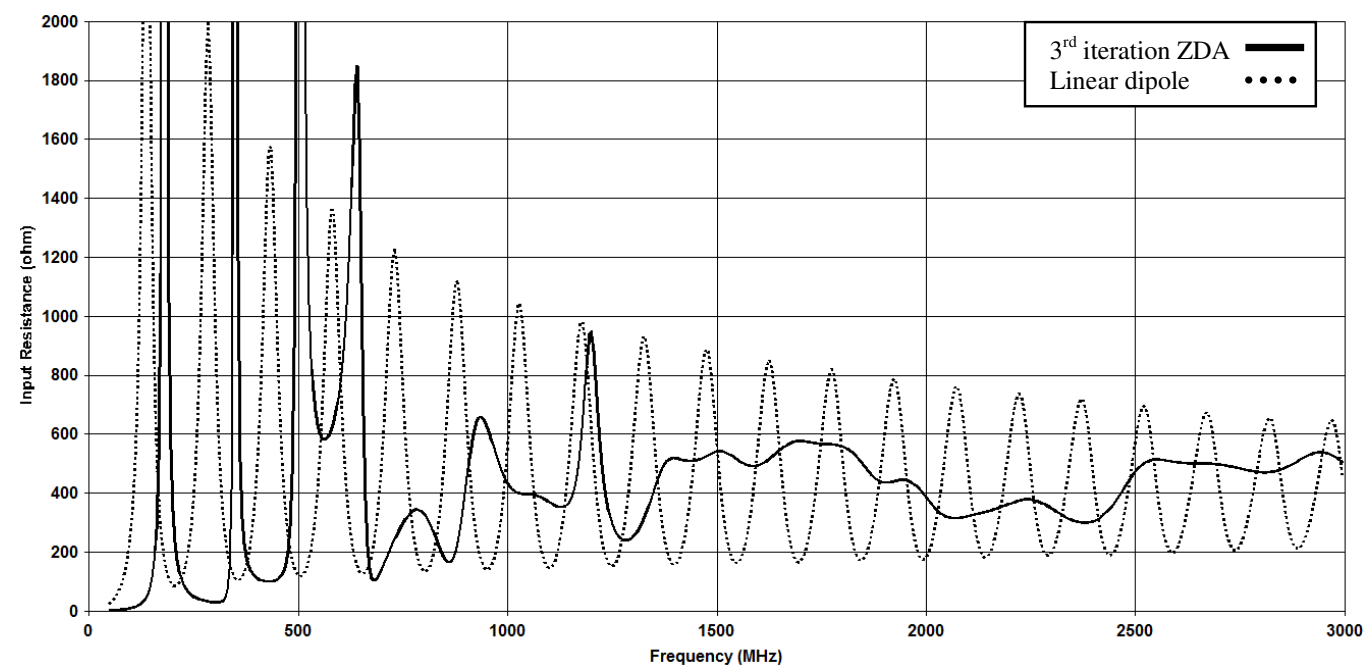

Figure 18. The input resistances of the third iteration of fractal ZDA and linear dipole with the same wire length

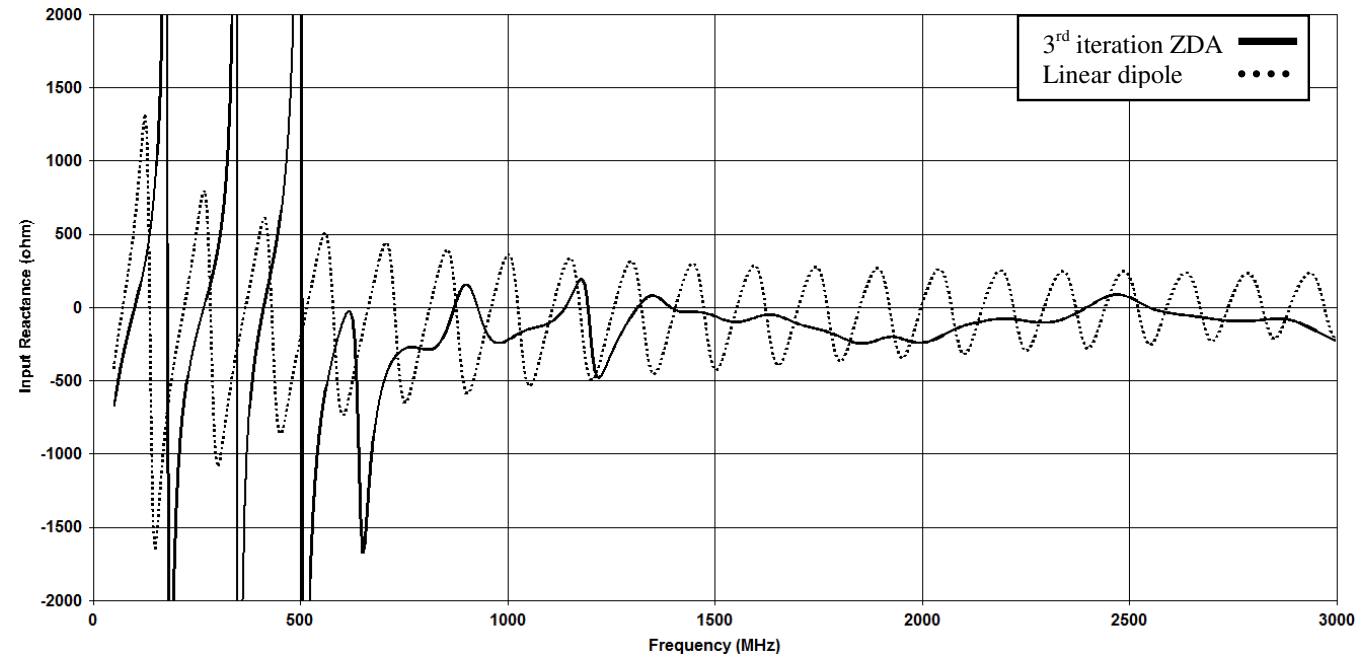

Figure 19. The input reactance of the third iteration of fractal ZDA and linear dipole with the same wire length 
International Journal of Network Security \& Its Applications (IJNSA), Vol.5, No.5, September 2013

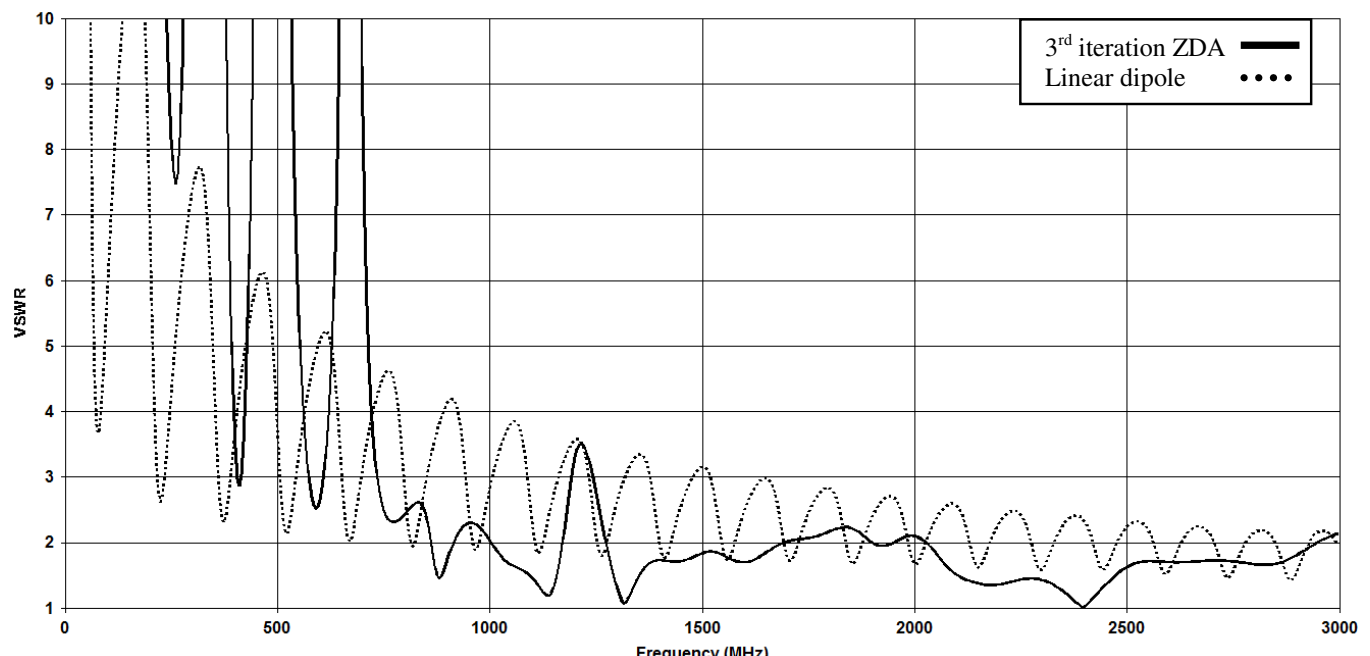

Figure 20. The VSWR of the third iteration of fractal ZDA and linear dipole with the same wire length at $\mathrm{Z}_{\circ}=300$

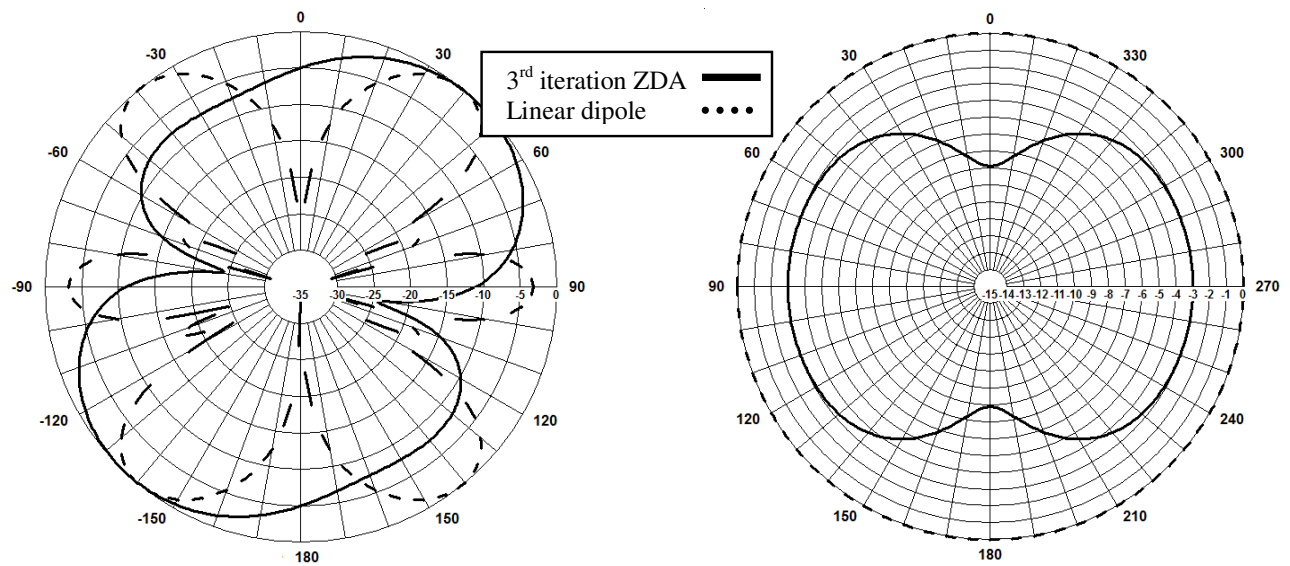

Figure 21. Power radiation pattern in $x z$-plane at $400 \mathrm{MHz}$

Figure 22. Power radiation pattern in $x y$ - plane at $400 \mathrm{MHz}$

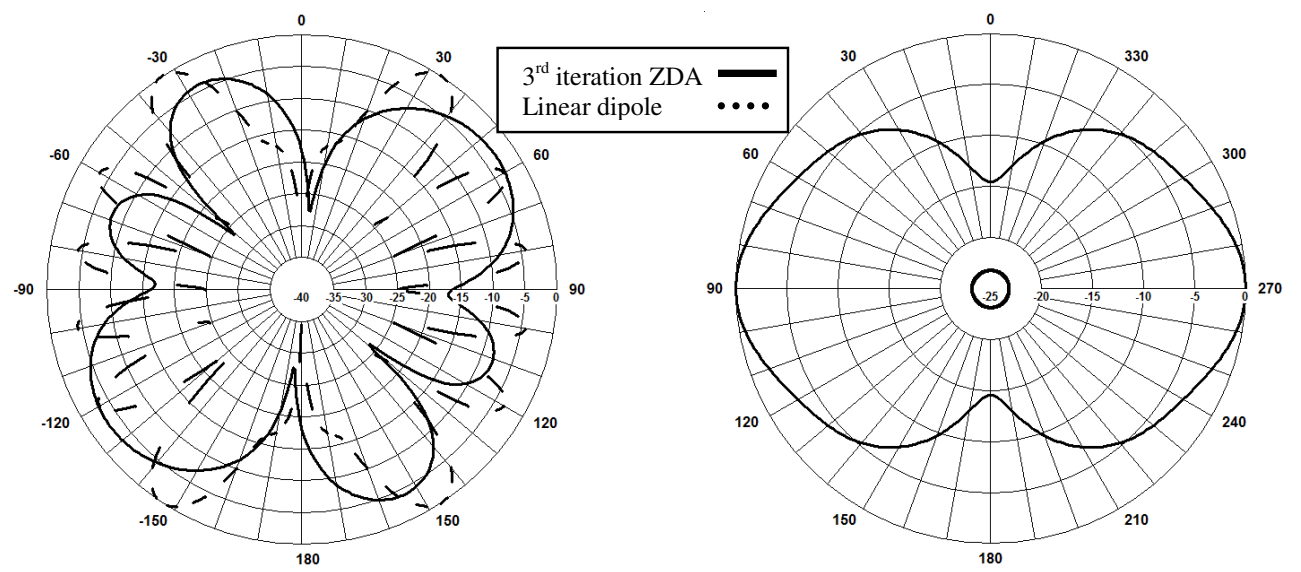

Figure 23. Power radiation pattern in $x z$-plane at $900 \mathrm{MHz}$

Figure 24. Power radiation pattern in $x y$ - plane at $900 \mathrm{MHz}$ 
International Journal of Network Security \& Its Applications (IJNSA), Vol.5, No.5, September 2013

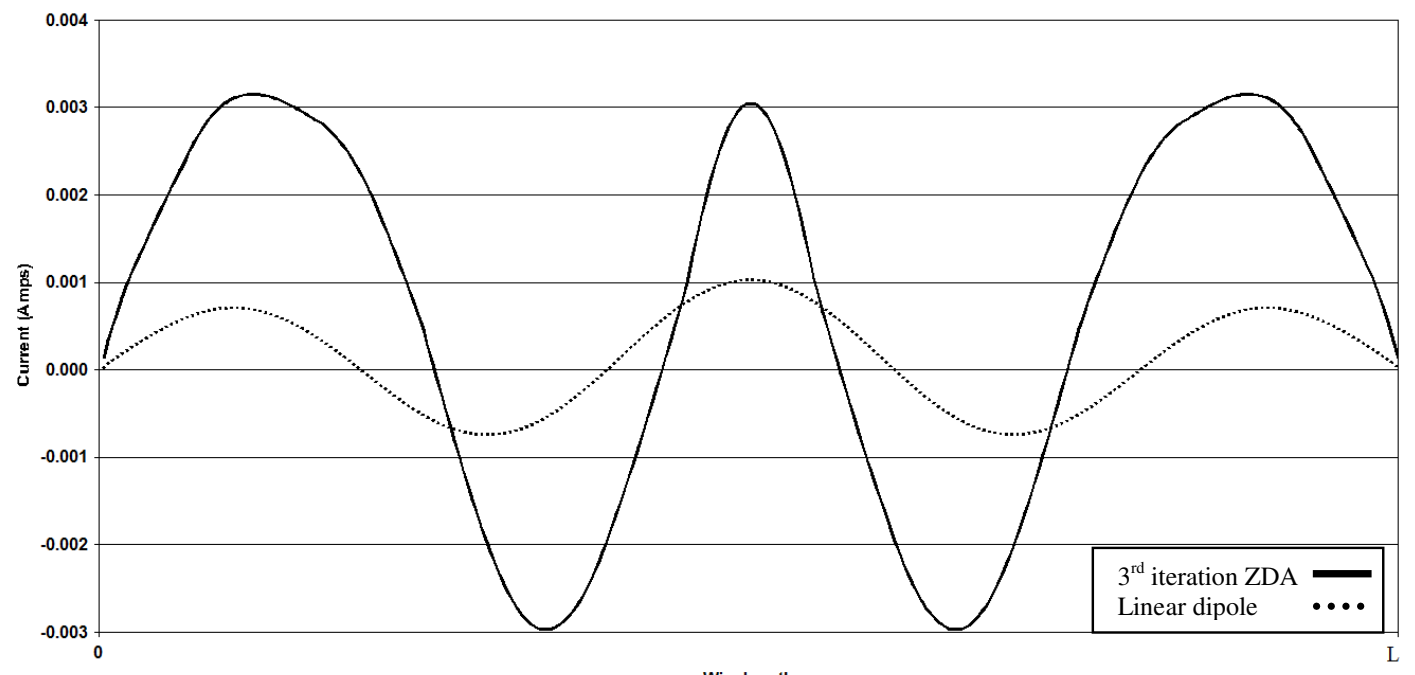

Figure 25. The current distribution of the third iteration of fractal ZDA and linear dipole with the same wire

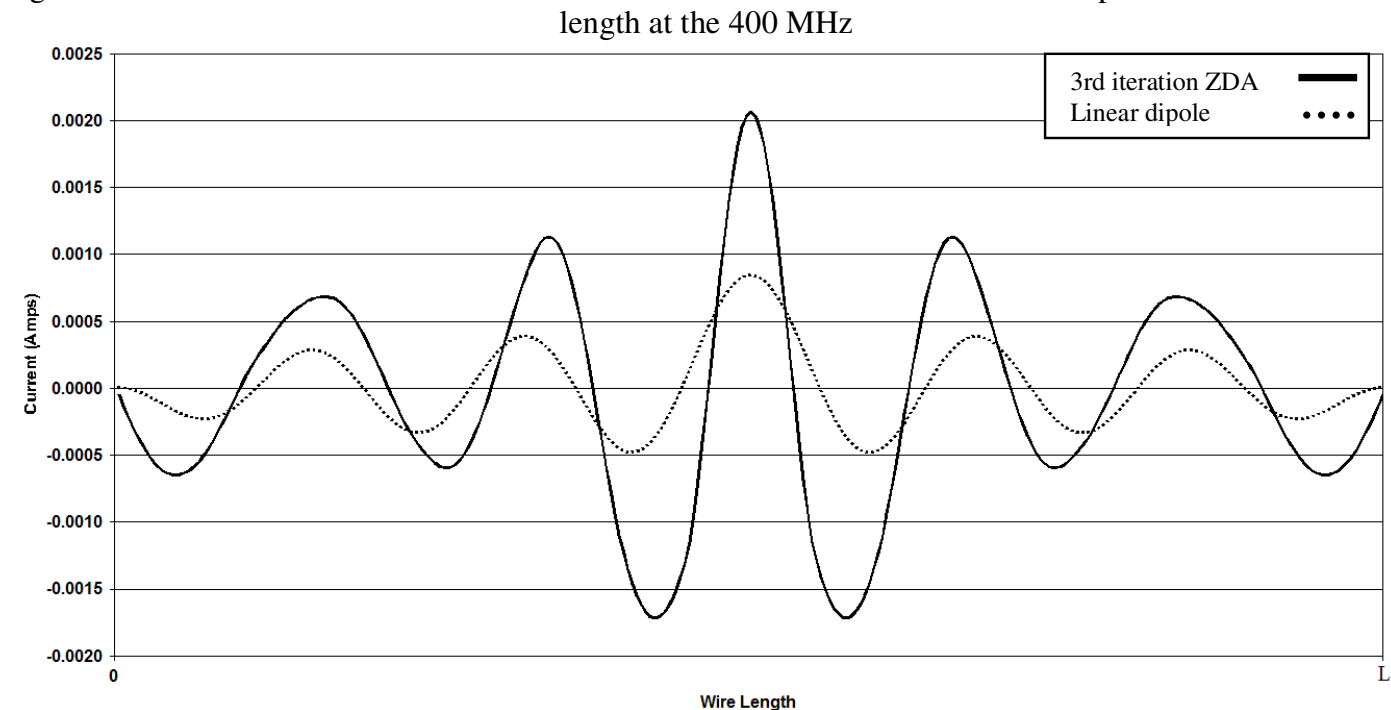

Figure 26. The current distribution of the third iteration of fractal ZDA and linear dipole with the same wire length at the $900 \mathrm{MHz}$

From the previous figures we notice that the fractal ZDA has superior performance over the linear dipole. The linear dipole is resonant antenna but fractal ZDAs show broad characteristics. The fractal ZDA has superior current distribution at the linear dipole. The main difference between these two antennas is the polarization where the linear dipole is linearly polarized antenna $[1,2]$ but fractal Z-shaped dipole antenna is elliptically polarized antenna.

\section{Conclusions}

A new simple wire antenna is proposed and analyzed, namely the Z-shaped dipole antenna and fractal Z-shaped dipole which radiates left elliptically polarized (LEP) waves. Also the comparison between the third iteration Z-shaped dipole antennas and the linear dipole is presented. The analysis of the antenna is performed using the MoM. The field patterns and gains in the principal planes are obtained. Also the other radiation characteristics such as input 
International Journal of Network Security \& Its Applications (IJNSA), Vol.5, No.5, September 2013

resistance, reactance and the VSWR as functions of frequency are reported. The results show that the proposed antennas are very promising to be used in the VHF and UHF frequency ranges.

\section{REFERENCES}

[1] C.A. Balanis, (2005)“Antenna Theory Analysis and Design” third edition (John Wiley \& Sons).

[2] Yi Huang and Kevin Boyle, (2008) "Antennas from Theory to Practice" first edition (John Wiley \& Sons).

[3] Benoit B. Mandelbrot, (1977) "The Fractals Nature of Geometry", New York, W. H. Freeman and Company.

[4] Douglas H. Werner and Raj Mittr, (2000) "Fontiers in Electromagnetis" New York, IEEE Press.

[5] Rajeev Mathur, Sunil Joshiand Krishna C Roy, (2010) "A Novel Multiband Koch Loop Antenna Using Fractal Geometry For Wireless Communication System" International Journal of Wireless \& Mobile Networks (IJWMN) Vol. 3, No. 5.

[6] Li, D. and J.-F. Mao, (2012)"Koch-like sided Sierpinski gasket multifractal dipole antenna," Progress In Electromagnetics Research , Vol. 126, 399-427.

[7] LIi Daotie and Mao Junfa , (2013 “" Multiband Multimode Arched Bow-Shaped Fractal Helix Antenna” Progress In Electromagnetics Research, Vol. 141.

[8] John P. Gianvittorio and Yahya Rabmat-Samii, (2002 )"Fractal Antennas: A novel Antenna Miniaturization Technique, and Applications,” IEEE Antennas and Propagation Magazine, pp. 20-36.

[9] John Gianvittorio, (2003 )“Fractals, MEMS, and FSS Electromagnetic Device: Miniaturization and Multiple Resonances," PhD dissertation, University of California, Los Angeles.

[10] The NEC-2 Manual from (http://www.traveller.com/ richesop/nec/). 